\title{
Studies on Howard Goldblatt's Translation Works with the Application of Adaptation and Selection in Translation
}

\author{
Shuxin Dong, Qian Zhang
}

Changchun Institute of Technology, Changchun, Jilin, China.

\begin{abstract}
Keywords: Three-dimensional transformation; Eco-translatology; eco-environment; adaptation;
\end{abstract} selection.

\begin{abstract}
The essence of the Approach to Translation as Adaptation and Selection is "a translator's adaptation and selection activities in a translational eco-environment", which is called "three-dimensional transformation" and it centers on adaptive selection transformation in linguistic, cultural and communicative dimensions under the principle of multi-dimensional adaptation and adaptive selection. With the application of Approach to Translation as Adaptation and Selection, this paper illustrates Goldblatt's translation works of Death by Sandalwood and Life and Death Are Wearing Me Out to analyze Goldblatt's adaptation and adaptive selection in his translation.
\end{abstract}

\section{Introduction}

$\mathrm{Hu}$ Gengshen argues that translating activities actually happen in a "translational eco-environment", which refers to the worlds of the source text and source/target languages, including the linguistic, communicative, cultural and social respects of translating, as well as the readers, the client, and author. The translational eco-environment here includes both the source-language and the target-language systems. The translation theory of Adaptation and Selection is a ground-breaking theory and has made its influences and contributions to the translation field. Though scholars' interest has been aroused by this approach, there only exist limited studies and theses that focus on figuring out translation issues by using this approach. It is in great demand of deep-level studies and researches which can interpret this approach that is of use and assist people to get a better understanding of it as well as use it to lead their translation process. And appropriate translation works are in great demand to be analyzed with the application of this approach. This paper undertakes the analysis of Goldblatt's translation and his role in the process of translation. As an excellent translator, Howard Goldblatt has dedicated himself to spreading Mo's works to the foreign countries and is honored as "the chief translator of modern and contemporary Chinese novel" owing to his efforts in translating Chinese novels.

\section{Translational Eco-Environment of Source Text}

"A translational eco-environment' refers to the worlds of the source text and the source/target languages, including the translating in linguistic, communicative, cultural and social respects, as well as the readers ,the client ,and author.” Both the source-language and the target-language systems comprise the translational eco-environment.

(1) Tanxiang xing The social environment in Tanxiang xing was chaotic and political factors were involved through the whole story. The historical backgrounds of the novel are following:(1)The Germans built Jiaoji Railway in Shandong. (2) Yuan Shikai suppressed the Boxer Rebellion in Shandong.(3)The Eight-Power Allied Forces attacked Beijing.(4)Cixi run away in panic. At that special period, Germany forced the Qing government to sign Jiao'ao lease treaty. In order to bring Shandong into its sphere of influence as soon as possible and plunder the rich mineral resources in Shandong, Germany began to conduct Railway survey and Road planting. Jinan Railway Survey extended to the west area in Gaomi.

In the process of exploration and planting, Germans bought farmland at low prices, forcing farmers to move their houses and graves, which was strongly opposed by farmers along. Lives of 
Chinese people were the most faithful reflection of the changing political situation. In the original novel, lives during that special period are really reproduced by languages filled with local color. Nevertheless, these characteristic languages in the meantime would make it harder to translate. It is imperative to transform the connotations in the linguistic dimension and those hiding in the cultural dimension and the communicative dimension.

(2) Life and Death Are Wearing Me Out Set in the Chinese land reform movement, this novel is about a landlord who was executed by shooting that attracts the attentions of readers a lot. The landlord is reincarnated in the form of some animals which are monkey, pig, donkey, ox and dog. A host of movements happened in China under Communist Party's rule have been witnessed by Ximen Nao through his reincarnation. He doesn't shun the odious and darkness. Through the evil respect in the rural areas, he gives analysis on mankind's soul and entire society. Life and Death Are Wearing Me Out is one of Mo Yan's conventional themes with more specific angle of view. Showing the tremendous changes happening in the rural areas in Northern China since 1950s, Mo Yan tells the story mainly from the prospective of human beings' and animals' viewpoints. Through this novel, Mo Yan hints that although the pattern of production in the rural areas has taken great place, traditional customs still exist.

\section{Translational Eco-Environment of Target Text}

The translation of literary text is diverse from translation of practical text because the former has higher standard. The translator ought to equip themselves with abundant knowledge of Chinese religion, philosophy, history, customs and art. He is in need of making a multitude of adaptation and selection, doing his best to make it smooth and true to the original in order to well translate the source language into the target text.

\subsection{Goldblatt's Selective Adaptation}

As the saying "the survival of the fittest" goes, people who can adapt to the environment most could survive and develop. It also applies to the translation. Those translations that can fit the translational eco-environment could survive for good. In the first place, the translator ought to make selective adaptation to adapt to those elements and factors with regard to the translational environment in order to activate their works. In An Approach to Translation as Adaptation and Selection, Professor Hu summarized the translator's adaptation to three main points, namely to personal needs, to translator's competence and to the translational environment.

\subsubsection{Adaptation to Personal Needs}

Since the translation is a "translator's adaptation and selection activities in a translational eco-environment", the translator should adapt to the translational eco-environment and select the source text with his or her own reason, including his or her needs for living, personal interest and preference, political intention, the pursuit for achievement and so on. It can be found that Goldblatt really adores both China and Chinese literature after reading his interviews and biography. In Goldblatt's flat, on the wall hangs a lot of Chinese paintings and calligraphy. While being the head of department, he also set up the Institution of Modern Chinese Literature in San Francisco State University. In addition, he is versatile because he can speak fluent mandarin and is adept in writing pretty Chinese characters. His passion for Chinese literature and culture can be seen from the above part. He once put it "when I see a Chinese novel I appreciate very much, I get the strong urge and need to translate it into English". Goldblatt' choosing of the novels shows his own inclination and the sphere he focuses on.

\subsubsection{Adaptation to Translator's Competence}

Hu Gengshen expounds that the translator ought to choose the source language that is in accord with his own competence to ensure the survival of his translation in An Approach to Translation as Adaptation and Selection.

Howard Goldblatt is praised as one of the most significant translators of Chinese literature who had more than 20 years of experience in learning and teaching in China. He owned firm foundations in language and deep knowledge about Chinese culture with the assistance of these experiences. In 
possession of the strong bilingual and bi-cultural ability, he could grasp a full understanding of the literal meaning,especially the deeper connotations hiding in the sentences. Goldblatt's bilingual competence was belauded by Scholars such as Liu Wuji, a noted Chinese American professor also the doctoral supervisor of Goldblatt. Apart from translating Chinese into English, two books written in Chinese were published by Goldblatt, namely, On Chinese New in 1980 and Nong Fu in 1981. Therefore, Goldblatt's choosing Tanxiang xing and Sheng Si Pi Lao to translate adapts to his own competence and capacity. It was the adaptation that serves as the foundation and a warrant for the triumph of translation versions Death by Sandalwood and Life and Death Are Wearing Me Out.

\subsubsection{Adaptation to Translational Eco-Environment}

At the period of “cultural turn" in 1980s, it is not abundant for Goldblatt's translation practice to back his reconstruction in a breeze in his novel translation. In Goldblatt's early career, an adaptation to the criterion and a subconscious appreciation of the source language were exhibited by his translation confined by the external translational environment. When translating Tanxiang xing and Sheng Si Pi Lao into Death by Sandalwood and Life and Death Are Wearing Me Out, Goldblatt has changed the external translational eco-environment much, and made it be more open-minded and liberal. Besides, with the rapid development and increasingly significant role in international community recently, China is in need of competent translators to spread Chinese literature abroad. On this occasion, Goldblatt and his translation could be more focused.

\subsection{Goldblatt's Adaptive Selection}

The excellent translation versions of Death by Sandalwood and Life and Death Are Wearing Me Out revealed that Goldblatt possesses extraordinary translation ability. His translation ought to be studied and provide guidance for other Chinese-English literature translation practices. In the theory Approach to Translation as Adaptation and Selection, the interpretation of translation ways is divided into three dimensions which are linguistic dimension, cultural dimension and communicative dimension. In the sections below, the paper will give analysis on Goldblatt's translation of Tanxiang xing and Sheng Si Pi Lao in three dimensions.

\subsubsection{Selections in Linguistic Dimension}

In Mo Yan's Tanxiang Xing and Sheng Si Pi Lao, a lot of expressions are full of strong local flavors and colors. For the translator, fully transferring the gorgeous and unique linguistic style was an arduous task. In the following part, the author will analyze the way that Goldblatt smoothed away difficulties in the linguistic dimension and made his choices in his translation. In the linguistic dimension, the translator's adaptation and selection emerges from various respects and levels including lexical level, syntactic level, textual level, simile, metaphor and so on. Let's see the following examples:

In numerous Mo's works, the discreetly and wisely described objects were generally crops or common supplies. In most cases, these objects are remained by Goldblatt in his translation.

(1)SL:俺爹的嗓子, 沙襄的西瓜, 不知道迷倒过高密东北乡多少女人。(Mo, 2010:7)

TL: His voice, soft and pliable, like watermelon pulp, captivated scores of Northeast Gaomi Township beauties... (Goldblatt, 2013:8)

\section{(2)SL:一个小小的县令，芝麻粒大的个官儿… (Mo, 2010:37)}

TL: ...an insignificant County Magistrate, an official about as important as a sesame seed... (Goldblatt, 2013:47)

(3)SL:嫁出去的女儿泼出去的水 (Mo, 2010:202)

TL: Marrying off a daughter is like spilling a pail of water. (Goldblatt, 2013:258)

In these instances, both ontologies and vehicles are very distinct. Voice's comparison to watermelon expounds the softness and gaiety. At the same time, the translator likens County Magistrate to sesame seed whose meaning is small and insignificant. SL3, as a Chinese saying, denotes that a married daughter, like the spilled water, has left for good and her parents can no longer count on them. Goldblatt translates smiles in the source language into the same objects in the target language which remains the original image faithfully. Besides, for the purpose of ensuring target readers to get the correct image, Goldblatt specifies the similar features between the two compared 
objects, which can assist target readers to get better understandings. Eager to show more Chinese images to target readers, Goldblatt combined domestication and explanation to satisfy readers' demands.

\subsubsection{Selections in Cultural Dimension}

As is known to all, the target language culture will, inevitably and to various extents, make its influence in the translating process. Unconsciously, the target language culture will have an effect on the translator's judgment and the choices of words and translation methods. Since there are differences between the source language culture and the target language culture in nature and content, the translator should have an eye on the exchanges between two cultures so as to appropriately translate the inner meanings. Therefore, it is significant and necessary for a great transformation that could lessen cultural misunderstandings to the greatest extent and the translator is supposed to concentrate on the adaptation in a cultural dimension. In other words, in the process of translation, it is imperative to pay heed to the bilingual cultural connotation.

Cultural images can be taken as signs and emblems that embrace some special connotations or particular meanings. The cultural images are extraordinary strong in abstractness and rich in meanings. They abstractly reflect the specific culture of a region, a nation, or a country and they also play a significant role in carrying the cultural connotations.

The wisdom of a country's history and culture is shown through a number of cultural images. Many cultural images are linked to a country's tales and legends. They frequently showed up in the people's allegory, artistic and literary works, and gradually they became a kind of cultural emblem possessing fixed and unique cultural meanings.

In Death by Sandalwood and Life and Death Are Wearing Me Out, there are examples:

SL:太阳刚冒红的那个时辰, 就是它们见阎王的时候。(Mo, 2010:4)

TL: ...soon after the red rays of sun appeared, would mark the hour that they went to meet Yama, the King of Hell. (Goldblatt, 2013:4)

“阎王” is a Buddhism word. He dominates the underworld and takes charge of human's metempsychosis. In Buddhism legend, after death, human have to register in the underworld and accept the trial by Yama. Yama comes from Sanskrit. In translation, Goldblatt gives an explanation of Yama, and used the western image-_Hell” to replace the Chinese underworld. Thus it can have a better effect of understanding.

\subsubsection{Selections in Communicative Dimension}

The adaptive selection of communicative dimension means that the translator keeps an eye on the transformation of bilingual communicative intention. Translation is a cross-cultural activity, and all activities carry certain communicative intention. Thus, on the basis of the transformation from linguistic dimension and cultural dimension, the communicative transformation puts the focus of translation on the communicative intention in target text.

Different narrative features have different communicative objectives. How to deal well with narrative features will have a direct influence on the translation's effect. Thus, one translation work Death by Sandalwood is selected to study.

In Death by Sandalwood's first part, four major characters are involved. They all have entirely different narrative intonations. Mei Niang is a countryside woman so her knowledge is regarded to be trustless. Zhao Jia is a cruel executioner, so his morality is regarded to be doubtful. Xiaojia is brainless and his knowledge is unreliable. As for the Magistrate Qian Ding, his attitude is the most justice. In accordance with various features, Mo applies various languages to describe them. In the process of translation, Goldblatt keeps an eye on this characteristic and succeeds in reproducing their images.

$\mathrm{SL}$ : 不过俺也看出来了, 爹不是个善茬子。俺爹不是豆腐爹, 俺爹是个金刚爹。(Mo, 2010:49)

TL: On the other hand, I could see that my dad was no pushover. He was hard as nails, not soft as bean curd... (Goldblatt, 2013:62)

It is Xiaojia who narrates this part. He is unwise and his words and behaviors are both very infantile. His words are simple and always very shallow. In SL2,“金刚”derives from Buddhism. 
Readers may not be unfamiliar with this, so the translator applies domestication. He shows the inner characteristics of “豆腐爹” and “金刚爹” that are respectively soft and hard. He also transforms the vehicle from “金刚” to “nails”, altering images from target culture which can remove the obstacles for understanding. Goldblatt selects numerous monosyllable and simple words to make it comply with Xiaojia's intelligence level.

Goldblatt's translation of these character names and sentences accurately maintains typical Chinese ideology in them, and also he does tough work to make it acceptable for readers. So readers can not only understand these metaphors in the sentences effortlessly but also gets to know certain Chinese ideology. In order to reach the communicative goal, translators have to consider readers' demands and simultaneously make adaptation and selection in linguistic and cultural dimensions.

\section{Conclusion}

The Approach to Translation as Adaptation and Selection has been analyzed in details in this paper, including its basic concepts, main features, translating principles and criterions, etc. With the application of the theory to the analysis of Howard Goldblatt's translation works, the author concludes that Howard Goldblatt has made a number of suitable adaptations and selections in his translation, in particular the transformation in three dimensions: First, in the linguistic dimension, Goldblatt has not only realized the semantic transformation, but more importantly, the transformation of the language style. Second, in the cultural dimension, he adapted to the translational eco-environment and made selective adaptations and adaptive selections between two different cultures. He combined domestication and foreignization together and made clever selections between these two methods. In some cases, he used domestication and followed the western cultures to lessen the obstacles in understanding. But still in some cases, he used foreignization and honestly exhibited the Chinese wonderful cultures before the western readers. Third, in communicative dimension, he committed himself to realizing the purpose of communication by the means of using different translation skills of character names and retention of different narrative features. The improved readability would make the translation version well welcomed and accepted.

\section{Acknowledgements}

The authors would like to give their thanks to Jilin Social Science Foundation (NO. 120170054) for its financial and technical support.

\section{References}

[1]. Baker, M. In Other Words: A Coursebook on Translation [M]. London: Routledge, 2011.

[2]. Bassnett, S\&Lefevere, A (eds.) Translation, History and Culture [M]. London: Pinter, 1990.

[3]. Chesterman, A. Memes of Translation: The Spread Of ideas in Translation Theory [M]. Amsterdam and Philadelphia: Benjamin, 1997.

[4]. Goldblatt, H. Life and Death Are Wearing Me Out [M]. New York: Arcade Publishing, 2008.

[5]. Gutt, E. Translation and Relevance: Cognition and Context [M]. Manchester: St Jerome Publishing, 2000.

[6]. Hu Gengshen. Translation as Adaptation and Selection [J]. Perspectives: Studies in Translatology, 2003, (4): 283-291.

[7]. Mo and Howard Goldblatt. Sandalwood Death [M]. Norman: University of Oklahoma Press, 2013. 